\title{
Multiple-antibiotic-resistant bacteria from cockroaches trapped from a public hospital and a nearby students' hostel in Accra, Ghana
}

\author{
Charles BROWN * and Abdul-Nasir ALHASSAN \\ Department of Medical Laboratory Sciences, School of Allied Health Sciences, University of Ghana, P. O. Box \\ KB143, Korle bu, Accra, Ghana. \\ *Corresponding author; E-mail: cabrown@chs.edu.gh; Tel: +233268203808
}

\begin{abstract}
The ability of cockroaches, found in and around hospital settings, to harbour multiple- antibioticresistant bacteria poses serious health implications. This study investigated and compared multiple-antibioticresistant bacteria carried by cockroaches from a hospital environment. Antibiotic susceptibility patterns of isolated pathogenic bacteria on the internal and external surfaces of trapped cockroaches showed that over $60 \%$ of the Gram negative enteric bacilli, >90\% of the 23 Pseudomonas aeruginosa and all three Gram positive bacteria isolates were resistant to at least four of the antibiotics tested. Necessary control measures need to be taken against the infestation of such facilities by cockroaches.
\end{abstract}

(C) 2014 International Formulae Group. All rights reserved.

Keywords: Multiple-antibiotic-resistant bacteria, cockroaches, hospital, hostel.

\section{INTRODUCTION}

Cockroaches, insects commonly seen as household pests, are generally regarded as a nuisance. However, the medical importance of cockroaches has been largely overlooked though they have been shown to harbour a number of pathogenic and non-pathogenic micro-organisms (Pai et al., 2004; Salehzadeh et al., 2007). Due to their omnivorous and voracious feeding habits and their indiscriminate defecation and regurgitation over human food, cockroaches are implicated in the spread of several infectious agents that humans acquire by ingestion.

Large numbers of, especially domestic and peridomestic cockroaches, can often be found in and around hospital wards, because such settings provide the moisture, a ready source of food, warmth and darkness that allow cockroaches to hide and multiply. Their ability to strive within hospital settings is also partly due to the slow and/or inefficient clearance of medical waste (Fakoorziba et al., 2010). These insects are potential carriers of bacteria that are often involved in nosocomial infections (Salehzadeh et al., 2007). Oliva et al. (2010), in a hospital in Havana, Cuba, collected cockroaches that carried the same Gram negative enteric bacteria as some patients.

Several species of bacteria have been isolated from cockroaches in different studies (Pai et al., 2004; Fakoorziba et al., 2010). Gram negative bacteria such as Pseudomonas aeruginosa, Klebsiella pneumonia, Enterobacter spp. and Escherichia coli 
(Salehzadeh et al., 2007), and Gram positive bacteria, such as Staphylococcus aureus and Enterococcus spp. (Pai et al., 2004; Salehzadeh et al., 2007) have all been isolated from cockroaches. These bacteria were often found on the cuticle and/or in the alimentary canal of the cockroaches (Elgderi et al., 2006).

This study investigated and compared the potential carriage by cockroaches of multiple-antibiotic-resistant pathogenic bacteria at the main kitchen of a public hospital and a nearby hostel both in Accra, Ghana.

\section{MATERIALS AND METHODS}

Sampling sites and sample collection

Cockroaches were collected, from the main kitchen of the hospital and the balconies of the hostel rooms from May-June, 2011, using sugar-baited traps placed overnight at suitable positions at the sampling sites. Each trapped cockroach was transferred, with the aid of a pair of forceps, into a sterile Eppendorf tube and the tube capped, transported to the laboratory and immobilized by chilling at $0{ }^{\circ} \mathrm{C}$ for 5 minutes.

Preparation of bacterial suspensions from the external surface of trapped cockroaches

Each immobile cockroach's body was washed thoroughly by being suspended in 7 $\mathrm{ml}$ of sterile phosphate-buffered saline (PBS, $\mathrm{pH}$ 7.2) and vortexed vigorously for $2-3$ minutes. The cockroach was removed from the PBS and checked for bacteria that were dislodged from the external surfaces of the insect.

Preparation of bacterial suspensions from the internal surface of trapped cockroaches

After washing in PBS, each cockroach was placed in a second sterile tube, first surface-sterilized in $70 \%$ alcohol for $5 \mathrm{~min}$, washed with sterile PBS for 2-3 minutes, and then macerated (in the tube) in $10 \mathrm{ml}$ sterile PBS with a sterile glass rod. The macerate was then vortexed vigorously for 2-3 minutes and the resultant suspension checked for bacteria from the inside of the cockroach.

\section{Culture and identification of bacteria}

Loopfuls of each of the bacterial suspensions from each cockroach were inoculated separately onto blood and MacConkey agar plates and incubated overnight at $37{ }^{\circ} \mathrm{C}$ and the colonies were identified following standard bacteriological procedures (Collee et al., 1996; Koneman et al., 1997). Briefly, a representative colony from each bacterial growth was studied briefly by its macroscopic morphology, Gram reaction and biochemical tests for catalase, coagulase, oxidase, indole, urease and motility. The ability of some of the bacteria to utilize citrate and ferment sugars (glucose, lactose and sucrose) was also determined using citrate agar and triple sugar iron agar respectively.

\section{Antibiotic susceptibility testing}

The antibiotic susceptibility of each isolated pathogenic bacterium was tested by the Clinical and Laboratory Standards Institute (CLSI) Kirby-Bauer disc diffusion (KBDD) method (Clinical Laboratory Standards Institute, 2006). Each solution prepared was inoculated on Mueller Hinton agar. Commercially obtained antibiotic discs, tetracycline $(30 \mu \mathrm{g})$, amikacin $(30 \mu \mathrm{g})$, cotrimoxazole $(25 \mu \mathrm{g})$, gentamicin $(10 \mu \mathrm{g})$, chloramphenicol $(10 \mu \mathrm{g})$, ampicillin $(10 \mu \mathrm{g})$, cefuroxime $(30 \mu \mathrm{g})$ and cefotaxime $(30 \mu \mathrm{g})$ were placed on each medium inoculated with a gram negative rod (GNR) except Pseudomonas and incubated for 16-18 hours at $35{ }^{\circ} \mathrm{C}$. Gram positive bacteria isolated were tested against gentamicin $(10 \mu \mathrm{g})$, penicillin $(10 \mu \mathrm{g})$, ampicillin $(10 \mu \mathrm{g})$, erythromycin (15 $\mu \mathrm{g})$, tetracycline $(30 \mu \mathrm{g})$, cotrimoxazole $(25$ $\mu \mathrm{g})$, cefuroxime $(30 \mu \mathrm{g})$ and flucloxacillin $(5$ $\mu \mathrm{g})$ and $P$. aeruginosa tested against gentamicin $(10 \mu \mathrm{g})$, amikacin $(30 \mu \mathrm{g})$, ciprofloxacin $(5 \mu \mathrm{g})$, chloramphenicol $(10$ $\mu \mathrm{g})$, cefotaxime $(30 \mu \mathrm{g})$, ampicillin $(10 \mu \mathrm{g})$, tetracycline $(30 \mu \mathrm{g})$ and cotrimoxazole $(25$ $\mu \mathrm{g})$. Zones of inhibition were measured and interpreted as per the CLSI guidelines. Cultures of $S$. aureus NCTC-6571 and $P$. 
aeruginosa NCTC-10662 were used as controls.

\section{Statistical analysis}

For each type of suspension (externalor internal- surface), the frequencies of positivity for bacteria considered medically important was compared using Student's ttest. The prevalence of carriage of each isolated bacterial species was compared between collection sites using Fisher's exact tests. A p-value $<0.05$ was considered indicative of a statistically significant difference.

\section{RESULTS}

Ten (10) different species of bacteria were recovered from a total of 20 (10 from each site) cockroaches collected (Table 1). These included three Gram positive bacteria and seven Gram negative enteric bacilli. Pseudomonas aeruginosa, Enterobacter spp and Citrobacter spp were the predominant species of pathogenic bacteria among both the hospital and hostel cockroaches. There was a significant difference in the positivity of hospital and hostel cockroaches for $P$. aeruginosa and Citrobacter spp (Fisher's exact test, $\mathrm{P}=0.01$ and 0.03 respectively.
Each cockroach was positive for at least one of the 10 identified bacterial species. There was no statistical significant difference $(\mathrm{P}=$ 0.36) in positivity for the isolation of medically important bacteria between the suspension types. However, more bacteria were isolated from the internal surface suspensions $(54.05 \%)$ than from the external surface suspensions (45.95\%).

All three Gram positive bacteria isolated were resistant to at least four of the antibiotics tested; all were resistant to ampicillin, erythromycin and tetracycline. Over $60 \%$ of the Gram negative enteric bacilli isolates (21 from hospital cockroaches and 17 from hostel cockroaches) were found to be resistant to at least four of the eight antibiotics tested (Table 2). More than $90 \%$ of these enteric bacilli were susceptible to gentamicin and amikacin. Over $90 \%$ of the $23 P$. aeruginosa isolates recovered (16 from hospital cockroaches and seven from hostel cockroaches) were resistant to at least four of the antibiotics tested (Table 3). All $P$. aeruginosa isolates were susceptible to amikacin and ciprofloxacin but resistant to ampicillin and tetracycline.

Table 1: Number and species of bacteria isolated from cockroaches collected from the hospital kitchen and hostel balconies.

\begin{tabular}{lccc}
\hline Bacteria species isolated & $\begin{array}{c}\text { Hospital Kitchen } \\
(\mathbf{n = 1 0})\end{array}$ & $\begin{array}{c}\text { Hostel Balconies } \\
(\mathbf{n}=\mathbf{1 0})\end{array}$ & p-Value \\
\hline Staphylococcus epidermidis & 6 & 5 & $\mathrm{NS}$ \\
Staphylococcus aureus & 0 & 1 & $\mathrm{NS}$ \\
Streptococcus spp. & 1 & 0 & $\mathrm{NS}$ \\
Pseudomonas aeruginosa & 9 & 3 & 0.01 \\
Enterobacter spp. & 6 & 2 & $\mathrm{NS}$ \\
Citrobacter spp. & 7 & 2 & 0.03 \\
Salmonella spp. & 1 & 0 & $\mathrm{NS}$ \\
Acinetobecter spp. & 2 & 0 & $\mathrm{NS}$ \\
Eschericia coli & 1 & 2 & $\mathrm{NS}$ \\
Klebsiella spp. & 0 & 2 & $\mathrm{NS}$ \\
\hline TOTAL & $\mathbf{3 3}$ & $\mathbf{1 7}$ & \\
\hline
\end{tabular}

NS, Not Significant (p-value > 0.05). 
Table 2: Antibiotic resistance of the enterobacteria isolated from cockroaches from the hospital kitchen and hostel balconies.

\begin{tabular}{lccc}
\hline \multirow{2}{*}{ Antibiotic } & \multicolumn{3}{c}{ Number (\%) resistant } \\
\cline { 2 - 4 } & $\begin{array}{c}\text { Hospital Kitchen } \\
(\mathbf{n}=\mathbf{2 1})\end{array}$ & $\begin{array}{c}\text { Hostel Balconies } \\
(\mathbf{n}=\mathbf{1 7})\end{array}$ & Total (n= 38) \\
\hline Tetracycline & $14(66.7)$ & $15(88.2)$ & $29(76.3)$ \\
Gentamicin & $2(9.5)$ & $1(5.9)$ & $3(7.9)$ \\
Chloramphenicol & $15(71.4)$ & $12(70.6)$ & $27(71.0)$ \\
Amikacin & $1(4.8)$ & $0(0)$ & $1(2.6)$ \\
Ampicillin & $17(80.9)$ & $16(94.1)$ & $33(86.8)$ \\
Cefotaxime & $9(42.9)$ & $3(17.6)$ & $12(31.6)$ \\
Cefuroxime & $16(76.2)$ & $8(47.1)$ & $24(63.2)$ \\
Cotrimoxazole & $7(33.3)$ & $5(29.4)$ & $12(31.6)$ \\
\hline
\end{tabular}

Table 3: Antibiotic resistance of Pseudomonas aeruginosa isolated from the cockroaches from the hospital (kitchen) and SAHS hostel.

\begin{tabular}{lccc}
\hline \multirow{2}{*}{ Antibiotic } & \multicolumn{3}{c}{ Number (\%) resistant } \\
\cline { 2 - 4 } & $\begin{array}{c}\text { Hospital Kitchen } \\
(\mathbf{n}=\mathbf{1 6})\end{array}$ & $\begin{array}{c}\text { Hostel Rooms } \\
(\mathbf{n}=\mathbf{7})\end{array}$ & Total (n= 23) \\
\hline Gentamycin & $1(6.25)$ & $0(0)$ & $1(4.35)$ \\
Amikacin & $0(0)$ & $0(0)$ & $0(0)$ \\
Ciprofloxacin & $0(0)$ & $0(0)$ & $0(0)$ \\
Chloramphenicol & $15(93.75)$ & $7(100)$ & $22(95.7)$ \\
Cefotaxime & $6(37.5)$ & $2(28.57)$ & $8(34.78)$ \\
Ampicillin & $16(100)$ & $7(100)$ & $23(100)$ \\
Tetracyclin & $16(100)$ & $7(100)$ & $23(100)$ \\
Cotrimoxazole & $15(93.8)$ & $6(85.7)$ & $21(91.3)$ \\
\hline
\end{tabular}




\section{DISCUSSION}

Ten (10) different species of bacteria were recovered from a total of 20 (10 from each site) cockroaches collected (Table 1). These included three Gram positive bacteria and seven Gram negative enteric bacilli. Pseudomonas aeruginosa, Enterobacter spp and Citrobacter spp were the predominant species of pathogenic bacteria among both the hospital and hostel cockroaches. These bacteria are commonly associated with infections and the ability of both hospital and hostel cockroaches to carry them is worrying since they may play a role in the spread of infectious diseases (Pai et al., 2004, 2005; Oliva et al., 2010).

There was a significant difference in the positivity of hospital and hostel cockroaches for $P$. aeruginosa and Citrobacter spp (Fisher's exact test, $\mathrm{P}=0.01$ and 0.03 respectively). Each cockroach was positive for at least one of the 10 identified bacterial species. There was no statistical significant difference $(\mathrm{P}=0.36)$ in positivity for the isolation of medically important bacteria between the suspension types. However, more bacteria were isolated from the internal surface suspensions $(54.05 \%)$ than from the external surface suspensions $(45.95 \%)$. The rate of isolation from the alimentary tract has been found to be significantly higher than that from the external surface (Pai et al., 2004, 2005).

Cockroaches trapped from the main kitchen of the hospital and the hostel carried multiple-antibiotic-resistant bacteria, on their external or internal surfaces, some of which are commonly associated with human infections (Pai et al., 2004, 2005; Oliva et al., 2010). Both hospital kitchen and hostel cockroaches showed a potential of carrying similar bacteria, probably because both sampling areas were food preparation areas (kitchen of hospital and balconies of hostel rooms, where students cook and keep leftover food).

All three Gram positive bacteria isolated were resistant to at least four of the antibiotics tested; all were resistant to ampicillin, erythromycin and tetracycline. Over $60 \%$ of the Gram negative enteric bacilli isolates (21 from hospital cockroaches and 17 from hostel cockroaches) were found to be resistant to at least four of the eight antibiotics tested (Table 2). More than 90\% of these enteric bacilli were susceptible to gentamicin and amikacin.

Over $90 \%$ of the $23 \mathrm{P}$. aeruginosa isolates recovered (16 from hospital cockroaches and seven from hostel cockroaches) were resistant to at least four of the antibiotics tested (Table 3). The cockroaches may therefore play an important role in spreading multiple-antibiotic-resistant Pseudomonas in both the hospital and surrounding buildings (Elgderi et al., 2006; Saitou et al., 2009). However, all $P$. aeruginosa isolates were susceptible to amikacin and ciprofloxacin but resistant to ampicillin and tetracycline.

There was a significant difference in the positivity of hospital and hostel cockroaches for $P$. aeruginosa and Citrobacter spp showing a clearly significant geographical (or perhaps environmental) variation in the bacteria carried by cockroaches. Since the kitchen is in closer proximity to the wards, cockroaches there could easily access the wards and other infectious areas of the hospital. In a study by Saitou et al. (2009), P. aeruginosa was frequently isolated from cockroaches captured in locker rooms and kitchens.

Despite the lack of definitive evidence that cockroaches are vectors of bacterial agents causing human disease, the potential health risks associated with the ability of such insects to carry multipleantibiotic-resistant bacteria, necessitates the control of cockroaches in hospitals and necessary control measures need to be taken against the infestation of such facilities by cockroaches. It is recommended that further work be done over a longer period and on cockroaches directly collected from the wards of the hospital. 


\section{ACKNOWLEDGEMENTS}

We thank Mr Thomas Dankwah, Mrs Richael Smith and Mr Julian Okine for their valuable laboratory support.

\section{REFERENCES}

CLSI (Clinical Laboratory Standards Institute). 2006. Performance Standards for Antimicrobial Disk Susceptibility tests. Approved Standard (9th edn). CLSI: Wayne, PA.

Collee JG, Fraser AG, Marmion BP, Simmons A. 1996. Mackie \& McCartney Practical Medical Microbiology $\left(14^{\text {th }}\right.$ edn). Churchill Livingstone: New York.

Elgderi RM, Ghenghesh KS, Berbash N. 2006. Carriage by the German cockroach (Blattella germanica) of multipleantibiotic-resistant bacteria that are potentially pathogenic to humans, in hospitals and households in Tripoli, Libya. Ann. Trop. Med. Parasitol., 100: $55-62$.

Fakoorziba MR, Eghbal F, Hassanzadeh J, Moemenbellah-Fard MD. 2010. Cockroaches (Periplaneta americana and Blattella germanica) as potential vectors of the pathogenic bacteria found in nosocomial infections. Ann. Trop. Med. Parasitol., 104(6): 521-528

Koneman EW, Allen SD, Janda, WM, Schreckenberger PC, Winn WC. 1997.
Color Atlas and Textbook of Diagnostic Microbiology (5th edn). Lippincott Williams \& Wilkins: Philadelphia, PA.

Oliva GR, Diaz C, Fuentes Gonza'lez O, Martinez MD, Ferna'ndez C, Cordovi R et al. . 2010. Blattella germanica as a possible cockroach vector of microorganisms in a hospital. J. Hosp. Infect., 74: 93 - 95.

Pai HH, Chen WC, Peng CF. 2004. Cockroaches as potential vectors of nosocomial infections. Infect. Control. Hosp. Epidemiol., 25: 979 - 984.

Pai HH, Chen WC, Peng CF. 2005. Isolation of bacteria with antibiotic resistance from household cockroaches (Periplaneta americana and Blattella germanica). Acta Trop., 93(3): 259-265.

Saitou K, Furuhata K, Kawakami Y, Fukuyama M. 2009. Isolation of Pseudomonas aeruginosa from cockroaches Captured in hospitals in Japan, and their antibiotic susceptibility. Biocontrol Sci., 14(4): 155-159

Salehzadeh A, Tavacol P, Mahjub H. 2007. Bacterial, fungal and parasitic contamination of cockroaches in public hospitals of Hamadan, Iran. J. Vector Borne Dis., 44: 105 - 110. 